Proceeding Paper

\title{
Synthesis of Porphyrins with ABAB Symmetry from Dipyrromethanes as Potential Phototherapeutic Agents ${ }^{\dagger}$
}

\author{
Milena B. Boarini, María E. Pérez, María E. Milanesio and Edgardo N. Durantini * \\ IDAS-CONICET, Departamento de Química, Facultad de Ciencias Exactas, Físico-Químicas y Naturales, \\ Universidad Nacional de Río Cuarto, Ruta Nacional 36 Km 601, X5804BYA Río Cuarto, Argentina; \\ mile_boarini@hotmail.com (M.B.B.); eugeniaperez925@gmail.com (M.E.P.); \\ mmilanesio@exa.unrc.edu.ar (M.E.M.) \\ * Correspondence: edurantini@exa.unrc.edu.ar; Tel.: +54-358-4676157 \\ + Presented at the 24th International Electronic Conference on Synthetic Organic Chemistry, \\ 15 November-15 December 2020; Available online: https://ecsoc-24.sciforum.net/.
}

Citation: Boarini, M.B.; Pérez, M.E.; Milanesio, M.E.; Durantini, E.N. Synthesis of Porphyrins with ABAB Symmetry from Dipyrromethanes as Potential Phototherapeutic Agents. Chem. Proc. 2021, 3, 133. https://doi. org/10.3390/ecsoc-24-08305

Academic Editors: Julio A. Seijas and M. Pilar Vázquez-Tato

Published: 14 November 2020

Publisher's Note: MDPI stays neutral with regard to jurisdictional claims in published maps and institutional affiliations.

Copyright: (c) 2020 by the authors. Licensee MDPI, Basel, Switzerland. This article is an open access article distributed under the terms and conditions of the Creative Commons Attribution (CC BY) license (http://creativecommons.org/licenses/by/4.0/).

\begin{abstract}
Asymmetrically meso-substituted porphyrins were synthesized with ABAB symmetry patterns. The approach required the formation of dipyrromethanes, which were obtained from the condensation of an aldehyde (pentafluorobenzaldehyde, 4-nitrobenzaldehyde or N,N-diphenylaminobenzaldehyde) with a large excess of pyrrole (1:47 aldehyde/pyrrole mol ratio), catalyzed by trifluoroacetic acid in 70-94\% yields. Then, acid-catalyzed condensation of these dipyrromethanes with an aldehyde ( $N, N$-dimethylaminobenzaldehyde, 4-carboxymethyl benzaldehyde or $N$-ethyl-3carbazolecarbaldehyde) (1:1 mol ratio) in dichloromethane, followed by oxidation with 2,3-dichloro-5,6-dicyano-1,4-benzoquinone affords the diseased porphyrins in $10-42 \%$ yields. These ABAB-porphyrins are interesting starting materials to obtain photoactive molecular structures as potential phototherapeutic agents.
\end{abstract}

Keywords: porphyrin; tetrapyrrolic macrocycle; pyrrole; pentafluorophenyl; dipyrromethane; photosensitizer

\section{Introduction}

Porphyrin derivatives have been proposed as photosensitizers in the photodynamic inactivation of microorganisms [1,2]. However, depending on the substituents on the periphery of the tetrapyrrolic macrocycle, these molecules tend to aggregate, producing a loss of photodynamic activity. Thus, to achieve effective photoinactivation, these compounds can bind to different supports forming photoactive materials $[3,4]$. In this sense, it is interesting to develop porphyrins asymmetrically substituted in the meso positions by two different structures (A and B). In these compounds, structure $A$ has a functional group that allows covalent attachment to other molecules, while $B$ is substituted by groups, allowing changes in the properties of the tetrapyrrolic macrocycle [5,6].

A major limitation of available methods to synthesize porphyrins tetrapyrrole macrocycles is related to the possibility of attaching different groups at the four meso-positions of tetrapyrrole macrocycle. Porphyrins containing two types of meso-substituents can be synthesized by condensation of binary mixed aldehyde catalyzed by acid. However, this procedure is statistical in nature and frequently multiple porphyrins are formed [7]. In this case, six porphyrins can be obtained and the workup is complex due to the presence of subproducts. In general, the purification involves slowly chromatographic separation and no pure porphyrin is always possible, resulting in low yields of the desired product. More direct approaches to obtain trans-substituted porphyrins (ABAB-porphyrins) are provided by condensation of dipyrromethanes with aldehydes. This approach needs to 
obtain meso-substituted dipyrromethane that can be formed by the reaction of an aldehyde with pyrrole [8].

In the present work, $\mathrm{ABAB}$-porphyrins were synthesized from the condensation of meso-(substituted)dipyrromethanes with benzaldehyde derivatives catalyzed by acid. These porphyrins are interesting starting materials to obtain photoactive molecular structures as potential phototherapeutic agents.

\section{Materials and Methods}

\subsection{Equipment and Chemical Substances}

Proton nuclear magnetic resonance ( $\left.{ }^{1} \mathrm{HNMR}\right)$ spectra were carried out on an FTNMR Bruker Avance DPX400 spectrometer (Bruker BioSpin, Rheinstetten, Germany). Mass spectra were performed on a Bruker micrO-TOF-QII (Bruker Daltonics, MA, USA), using an ESI source (ESI-MS). Absorption and fluorescence spectra were achieved on a Shimadzu UV-2401PC spectrometer (Shimadzu Corporation, Tokyo, Japan) and a Spex FluoroMax spectrofluorometer (Horiba Jobin Yvon Inc, Edison, NJ, USA), respectively. Chemical substances were purchased from Sigma-Aldrich (Milwaukee, WI, USA). These compounds were used without further purification. Silica gel thin-layer chromatography (TLC, 250 microns) plates were obtained from Analtech (Newark, DE, USA), while silica gel 60 (0.040-0.063 mm, 230-400 mesh) was acquired from Merck (Darmstadt, Germany).

\subsection{Synthesis}

meso-(Pentafluorophenyl)dipyrromethane (1). Pentafluorobenzaldehyde $(0.55 \mathrm{~mL}$, $4.45 \mathrm{mmol})$ and pyrrole $(14.5 \mathrm{~mL}, 209 \mathrm{mmol})$ were purged with argon for $15 \mathrm{~min}$. Then, trifluoroacetic acid (TFA) $(70 \mathrm{~L}, 0.90 \mathrm{mmol})$ was added. The mixture was stirred for $45 \mathrm{~min}$ at room temperature. After that, the sample was diluted with $25 \mathrm{~mL}$ of dichloromethane (DCM) and three washes of $15 \mathrm{~mL}$ each were carried out with $\mathrm{NaOH}(0.1 \mathrm{M})$. The solvent and excess pyrrole were removed under reduced pressure using a rotary evaporator. The product was purified by flash column chromatography (silica gel, cyclohexane/ethyl acetate/triethylamine (TEA) 80:20:1), obtaining $1.31 \mathrm{~g}(94 \%)$ of $\mathbf{1}$. TLC (silica gel, cyclohexane/ethyl acetate/TEA 80:20:1) $R_{\mathrm{f}}=0.46 .{ }^{1} \mathrm{HNMR}\left(\mathrm{CDCl}_{3}, \mathrm{TMS}\right) \delta[\mathrm{ppm}] 5.88(\mathrm{~s}, 1 \mathrm{H}$, meso$\mathrm{H}), 6.00(\mathrm{~m}, 2 \mathrm{H}$, pyrrole- $\mathrm{H}), 6.15(\mathrm{q}, 2 \mathrm{H}$, pyrrole- $\mathrm{H}), 6.74(\mathrm{~m}, 2 \mathrm{H}$, pyrrole- $\mathrm{H}) 8.10$ (brs, $2 \mathrm{H}$, pyrrole NH). ESI-MS [m/z] $310.0534\left[\mathrm{M}^{+}\right]\left(310.0529\right.$ calculated for $\left.\mathrm{C}_{15} \mathrm{H}_{7} \mathrm{~F}_{5} \mathrm{~N}_{2}\right)$.

meso-(4-Nitrophenyl)dipyrromethane (2). A solution of 4-nitrobenzaldehyde (2.50 g, $16.6 \mathrm{mmol}$ ) and pyrrole ( $55 \mathrm{~mL}, 780 \mathrm{mmol}$ ) was degassed by bubbling with argon for $15 \mathrm{~min}$, and then TFA ( $321 \mu \mathrm{L}, 4.17 \mathrm{mmol}$ ) was slowly added. The solution was stirred for $20 \mathrm{~min}$ at room temperature. The crude product was diluted with DCM. The organic phase was washed with aqueous $0.1 \mathrm{M} \mathrm{NaOH}$. After that, the sample was washed with water. The solvent was removed under reduced pressure. The unreacted pyrrole was removed by vacuum distillation at room temperature. The product was purified by flash chromatography (silica gel, cyclohexane/ethyl acetate/triethylamine; 80:20:1) yielded $3.19 \mathrm{~g}(72 \%)$ of 2. ${ }^{1} \mathrm{HNMR}\left(300.08 \mathrm{MHz}, \mathrm{CDCl}_{3}, \mathrm{TMS}\right) \delta[\mathrm{ppm}] 5.58(\mathrm{~s}, 1 \mathrm{H}$, meso- $\mathrm{H}) ; 5.86(\mathrm{~m}, 2 \mathrm{H}$, pyrrole$\mathrm{H}) ; 6.17$ (q, 2H, pyrrole-H); $6.74(\mathrm{~m}, 2 \mathrm{H}$, pyrrole-H); 7.37 (d, 2H, J = 9.0 Hz); 8.01 (s, brs, $2 \mathrm{H}$, pyrrole $\mathrm{NH}) ; 8.16(\mathrm{~d}, 2 \mathrm{H}, \mathrm{J}=9.0 \mathrm{~Hz})$. ESI-MS [m/z] $267.1014\left[\mathrm{M}^{+}\right](267.1008$ calculated for $\left.\mathrm{C}_{15} \mathrm{H}_{13} \mathrm{~N}_{3} \mathrm{O}_{2}\right)$.

meso-[4-(N,N-Diphenylaminophenyl)]dipyrromethane (3). A solution of 4-(N,N-diphenylamino)benzaldehyde $(1.98 \mathrm{~g}, 7.24 \mathrm{mmol})$ and pyrrole $(24 \mathrm{~mL}, 340 \mathrm{mmol})$ was stirred under an argon atmosphere. This mixture was kept for $15 \mathrm{~min}$ at room temperature. Then, $140 \mu \mathrm{L}(1.82 \mathrm{mmol})$ of TFA was added and the mixture stirred for $30 \mathrm{~min}$. After that, $780 \mu \mathrm{L}(5.60 \mathrm{mmol})$ of triethylamine (TEA) was added and the solution was diluted with $50 \mathrm{~mL}$ of DCM. The solvent and pyrrole were removed by distillation under reduced pressure. The compound was isolated by flash column chromatography (silica gel, cyclohexane/ethyl acetate/TEA 80:20:1), yielding $1.97 \mathrm{~g}(70 \%)$ of 3 . TLC (silica gel, cyclohexane/ethyl acetate/TEA 80:20:1) $\mathrm{R}_{\mathrm{f}}=0.26 .{ }^{1} \mathrm{H}$ NMR $\left(\mathrm{CDCl}_{3}\right.$, TMS) $[\mathrm{ppm}] 5.43(\mathrm{~s}, 1 \mathrm{H}$, meso- 
$\mathrm{H}) ; 5.94(\mathrm{~m}, 2 \mathrm{H}$, pyrrole-H); 6.17(q, 2H, pyrrole- $\mathrm{H}) ; 6.72(\mathrm{~m}, 2 \mathrm{H}$, pyrrole-H); $6.94-7.12(\mathrm{~m}$, $10 \mathrm{H}, \mathrm{ArH}) ; 7.22$ (m, $4 \mathrm{H}, \mathrm{ArH}) ; 7.98$ (s, brs, 2H, pyrrole NH). ESI-MS [m/z] 389.1887 [M+] (389.1892 calculated for $\mathrm{C}_{27} \mathrm{H}_{23} \mathrm{~N}_{3}$ ).

5,15-di(4-(N,N-dimethylaminophenyl)-10,20-di(pentafluorophenyl)porphyrin (4). A solution of 4-(N,N-dimethylamino)benzaldehyde $(3.4 \mathrm{mmol})$ and dipyrromethane $\mathbf{1}(974 \mathrm{mg}$, $3.4 \mathrm{mmol}$ ) in $250 \mathrm{~mL}$ of DCM was bubbled with argon for $15 \mathrm{~min}$. Then, boron trifluoride etherate ( $\left.\mathrm{BF}_{3} \cdot \mathrm{OEt}_{2}, 1.1 \mathrm{mmol}\right)$ was added. The solution was stirred for $80 \mathrm{~min}$ at room temperature. After that, 2,3-dichloro-5,6-dicyano-1,4-benzoquinone (DDQ, $2.25 \mathrm{mmol}$ ) was added and the mixture was stirred for an additional $2 \mathrm{~h}$ at room temperature. The solvent was removed under reduced pressure and purification was performed by flash column chromatography (silica gel, DCM) giving 4 in $24 \%$ yield. ${ }^{1} \mathrm{HNMR}\left(\mathrm{CDCl}_{3}, \mathrm{TMS}\right) \delta[\mathrm{ppm}]$ -2.86 (s, brs, 2H, N-H), $3.05\left(\mathrm{~s}, 6 \mathrm{H}, \mathrm{N}\left(\mathrm{CH}_{3}\right) 2\right), 7.05(\mathrm{~d}, 4 \mathrm{H}, \mathrm{J}=8.2 \mathrm{~Hz}, 3,5-\mathrm{ArH}), 7.97(\mathrm{~d}, 4 \mathrm{H}$, $\mathrm{J}=8.2 \mathrm{~Hz}, 2,6-\mathrm{ArH}), 8.81-8.94\left(\mathrm{~m}, 8 \mathrm{H},-\right.$ pyrrole-H). ESI-MS $(\mathrm{m} / \mathrm{z}) 881.2447[\mathrm{M}+\mathrm{H}]^{+}$ (881.2451 calculated for $\mathrm{C}_{48} \mathrm{H}_{30} \mathrm{~F}_{10} \mathrm{~N}_{6}+\mathrm{H}$ ).

5,15-bis(4-Methoxycarbonylphenyl)-10,20-bis(pentafluorophenyl)porfirin (5). A solution of methyl 4-formylbenzoate $(632 \mathrm{mg}, 3.85 \mathrm{mmol})$ and dipyrromethane $\mathbf{1}(1.37 \mathrm{~g}, 4.38 \mathrm{mmol})$ in $450 \mathrm{~mL}$ of DCM was stirred for $15 \mathrm{~min}$ under argon atmosphere at room temperature. Then, TFA $(0.50 \mathrm{~mL}, 6.54 \mathrm{mmol})$ was added and the solution was kept stirring for $45 \mathrm{~min}$. The mixture was subsequently oxidized with DDQ $(885 \mathrm{mg}, 3.90 \mathrm{mmol})$ and stirred for $2 \mathrm{~h}$ in an atmosphere of air. Then, $20 \mathrm{~mL}$ of $\mathrm{MeOH}$ was added to remove excess DDQ and the mixture was kept stirred for $30 \mathrm{~min}$. The solvent was removed under reduced pressure. The product was purified by silica gel filtration and flash column chromatography (silica gel, cyclohexane/DCM 40\%), obtaining $90 \mathrm{mg}(10 \%)$ of $5 .{ }^{1} \mathrm{HNMR}\left(\mathrm{CDCl}_{3}, \mathrm{TMS}\right) \delta[\mathrm{ppm}]-$ $2.86(\mathrm{~s}, \mathrm{brs}, 2 \mathrm{H}, \mathrm{N}-\mathrm{H}), 4.13\left(\mathrm{~s}, 6 \mathrm{H}, \mathrm{COOCH}_{3}\right), 8.31(\mathrm{~d}, 4 \mathrm{H}, \mathrm{J}=8.0 \mathrm{~Hz}, 2,6-\mathrm{ArH}), 8.47(\mathrm{~d}, 4 \mathrm{H}$, $\mathrm{J}=8.0 \mathrm{~Hz}, 3,5-\mathrm{ArH}), 8.83-8.93\left(\mathrm{~m}, 8 \mathrm{H},-\right.$ pyrrole-H). ESI-MS $(\mathrm{m} / \mathrm{z}) 911.1720[\mathrm{M}+\mathrm{H}]^{+}$ (911.1716 calculated for $\mathrm{C}_{48} \mathrm{H}_{24} \mathrm{~F}_{10} \mathrm{~N}_{4} \mathrm{O}_{4}+\mathrm{H}$ ).

5,15-bis(4-Methoxycarbonylphenyl)-10,20-bis(4-nitrophenyl)porphyrin (6). A solution of methyl 4-formylbenzoate $(2.46 \mathrm{~g}, 15 \mathrm{mmol})$ and dipyrromethane $2(4.0 \mathrm{~g}, 15 \mathrm{mmol})$ in $1.5 \mathrm{~L}$ of DCM was purged with argon for $15 \mathrm{~min}$. Then, TFA $(1.85 \mathrm{~mL}, 24 \mathrm{mmol})$ was added slowly over $30 \mathrm{~s}$. The solution was stirred for $30 \mathrm{~min}$ at room temperature. After that, DDQ (3.4 g, $15 \mathrm{mmol}$ ) was added and the mixture was stirred for $2 \mathrm{~h}$ at room temperature. The solvent was removed under vacuum and flash column chromatography (silica gel, DCM) yielded $1.29 \mathrm{~g}(21 \%)$ of $6 .{ }^{1} \mathrm{HNMR}\left(\mathrm{CDCl}_{3}, \mathrm{TMS}\right) \delta[\mathrm{ppm}]-2.77(\mathrm{~s}, \mathrm{brs}, 2 \mathrm{H}$, $\mathrm{N}-\mathrm{H}), 4.14\left(\mathrm{~s}, 6 \mathrm{H}, \mathrm{COOCH}_{3}\right), 8.31(\mathrm{~d}, 4 \mathrm{H}, \mathrm{J}=8.0 \mathrm{~Hz}, 2,6-\mathrm{ArH}-\mathrm{COOEt}), 8.40(\mathrm{~d}, 4 \mathrm{H}, \mathrm{J}=8.3$ $\mathrm{Hz}, 2,6-\mathrm{ArH}-\mathrm{NO}_{2}$ ); 8.47 (d, 4H, J = $\left.8.0 \mathrm{~Hz}, 3,5-\mathrm{ArH}-\mathrm{COOEt}\right), 8.65$ (d, 4H, J = $8.3 \mathrm{~Hz}, 3,5-$ ArH-NO $\left.{ }_{2}\right), 8.80-8.97\left(\mathrm{~m}, 8 \mathrm{H}\right.$, -pyrrole-H). ESI-MS (m/z) $820.1720[\mathrm{M}+\mathrm{H}]^{+}(820.1716$ calculated for $\left.\mathrm{C}_{48} \mathrm{H}_{32} \mathrm{~N}_{6} \mathrm{O}_{8}+\mathrm{H}\right)$.

5,15-Bis[4-(N,N-diphenylamino)phenyl]-10,20-bis[3-(N-ethylcarbazoyl)]porphyrin (7). A solution of $\mathrm{N}$-ethyl-3-carbazolecarbaldehyde $(0.56 \mathrm{~g}, 2.50 \mathrm{mmol})$ and dipyrromethane 3 $(1.00 \mathrm{~g}, 2.50 \mathrm{mmol})$ in $310 \mathrm{~mL}$ of DCM was purged with argon for $15 \mathrm{~min}$. After that, TFA (425 $\mu \mathrm{L}, 5.50 \mathrm{mmol}$ ) was slowly added and the solution was stirred for $60 \mathrm{~min}$ at room temperature. Then, DDQ $(1.50 \mathrm{~g}, 6.61 \mathrm{mmol})$ was added and the mixture was stirred for an additional $18 \mathrm{~h}$, open to the atmosphere. The solvent was removed under reduced pressure. The obtained product was purified by flash column chromatography (silica gel, hexane/DCM/TEA 6:93.8:0.2) obtaining $622 \mathrm{mg}(42 \%)$ of 7. TLC (silica gel, hexane/DCM/TEA 6:93.8:0.2) $\mathrm{Rf}=0.68 .{ }^{1} \mathrm{HNMR}\left(\mathrm{CDCl}_{3}, \mathrm{TMS}\right) \delta[\mathrm{ppm}]-2.60(\mathrm{brs}, 2 \mathrm{H}$, pyrrole N-H), $1.68(\mathrm{t}$, $\left.6 \mathrm{H},-\mathrm{CH}_{3}, \mathrm{~J}=7.1 \mathrm{~Hz}\right), 4.64\left(\mathrm{q}, 4 \mathrm{H},-\mathrm{CH}_{2}-\mathrm{J}=7.1 \mathrm{~Hz}\right), 7.15(\mathrm{~d}, 4 \mathrm{H}, \mathrm{J}=7.8 \mathrm{~Hz}), 7.34-7.50(\mathrm{~m}$, $22 \mathrm{H}), 7.52-7.64(\mathrm{~m}, 4 \mathrm{H}), 7.75(\mathrm{~d}, 2 \mathrm{H}, \mathrm{J}=8.3 \mathrm{~Hz}), 8.02(\mathrm{~d}, 4 \mathrm{H}, \mathrm{J}=7.8 \mathrm{~Hz}), 8.20(\mathrm{~d}, 4 \mathrm{H}, \mathrm{J}=$ $7.7 \mathrm{~Hz}), 8.34(\mathrm{~d}, 2 \mathrm{H}, \mathrm{J}=8.3 \mathrm{~Hz}), 8.82-9.06(\mathrm{~m}, 8 \mathrm{H},-$ pyrrole-H). ESI-MS [m/z] 1183.5169 $[\mathrm{M}+\mathrm{H}]^{+}\left(1183.5176\right.$ calculated for $\left.\mathrm{C}_{84} \mathrm{H}_{62} \mathrm{~N}_{8}+\mathrm{H}\right)$.

\subsection{Spectroscopic Studies}

Absorption and fluorescence spectra were performed in a quartz cell of $1 \mathrm{~cm}$ path length using $\mathrm{N}, \mathrm{N}$-dimethylformamide (DMF) at $25.0 \pm 0.5^{\circ} \mathrm{C}$. Absorbances $(<0.05)$ were 
matched at the excitation wavelength $(550 \mathrm{~nm})$ and the areas of the emission spectra were integrated in the range $600-800 \mathrm{~nm}$. The fluorescence quantum yield $\left(\Phi_{\mathrm{F}}\right)$ of the porphyrins was calculated by comparison of the area below the corrected emission spectrum of 5,10,15,20-tetrakis(4-methoxyphenyl)porphyrin (TMP) as a reference [5].

\section{Results and Discussion}

\subsection{Synthesis of Dipyrromethanes}

Aldehydes and pyrrole undergo acid-catalyzed condensation at room temperature. Therefore, the condensation of substituted benzaldehydes with a large excess of pyrrole (1:47 aldehyde/pyrrole mol ratio) catalyzed by TFA affords meso-(substituted)dipyrromethane (1-3). After $25 \mathrm{~min}$ of stirring at room temperature, the reaction mixture showed complete consumption of the starting aldehyde. In this procedure, pyrrole was used as a reactant in excess and as the solvent of the condensation, which yielded the corresponding dipyrromethane (Scheme 1).

The dipyrromethanes were purified by flash chromatography on silica gel in a mildly basic medium, using $n$-hexane/ethyl acetate/TEA (80/20/1). The presence of $1 \%$ TEA was necessary to avoid the acidolysis of the dipyrromethane on silica gel column. Dipyrromethanes 1, 2 and 3 were obtained in 94,72 and $70 \%$, respectively. These compounds are stable upon storage at $0{ }^{\circ} \mathrm{C}$ in nitrogen atmosphere and absence of light. Therefore, dipyrromethanes can be easily synthesized with good yield and high purity, which is crucial for the formation of asymmetric meso-substituted porphyrins.

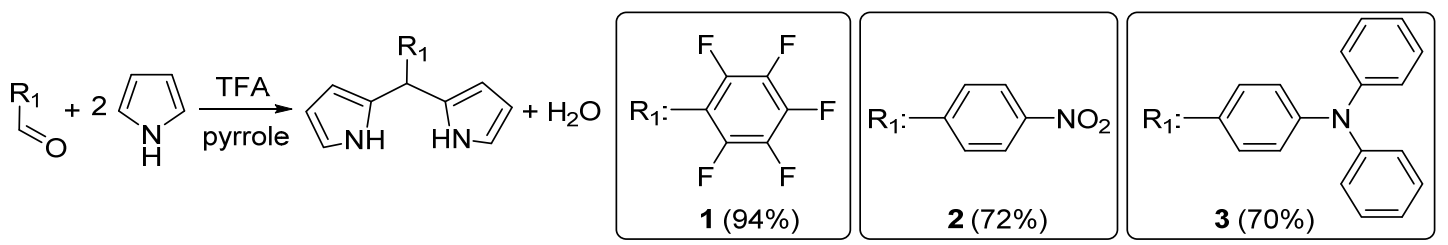

Scheme 1. Synthesis of dipyrromethanes $\mathbf{1}$ and $\mathbf{3}$.

\subsection{Synthesis of $A B A B$-Porphyrins}

ABAB-porphyrins 4-7 were synthesized by the acid-catalyzed condensation of dipyrromethane 1-3 and the correspondent substituted benzaldehyde (Scheme 2). Mixedbenzaldehyde dipyrromethane condensations were performed using about [1:1] molar relation of dipyrromethane and substituted benzaldehyde. The reaction was performed using catalytic among of TFA or $\mathrm{BF}_{3} \mathrm{OEt}_{2}$ and $\mathrm{DCM}$ as solvent at room temperature. The reaction mixture was subject to oxidation with DDQ. Thus, this mixed condensation affords the corresponding $\mathrm{ABAB}$-porphyrin.

These porphyrins were easily separated by flash chromatography with high purity using DCM/methanol gradient. In all these cases, the first purple band corresponds to the ABAB-porphyrin. Under these conditions, ABAB-porphyrins 4, 5, 6 and 7 were obtained in $24,10,21$ and $42 \%$ yields, respectively.

This procedure was previously used to obtain ABAB-porphyrins from the condensation of a dipyrromethane bearing a sterically hindered substituent with an aldehyde [9].

The pentafluorophenyl group linked to the meso position of the compounds 4 and 5 can be used to obtain porphyrin derivatives by nucleophilic aromatic substitution reaction of the para-fluorine atom $[3,10]$. Thus, this substituent was used to covalently link the porphyrin ring to several functionalized structures [4]. In porphyrin 4, N,N-dimethylaminophenyl substituent can be used to obtain cationic intrinsic charge by methylation [5]. In addition, aminophenyl substituents can be obtained in porphyrin 6 by reduction of nitrophenyl group [11]. Moreover, porphyrin 5 and $\mathbf{6}$ can be hydrolyzed to form carboxylic acid groups, which can be linked to several structures [11]. Finally, both electroactive substituents of porphyrin 7 can form different polymers [12]. 


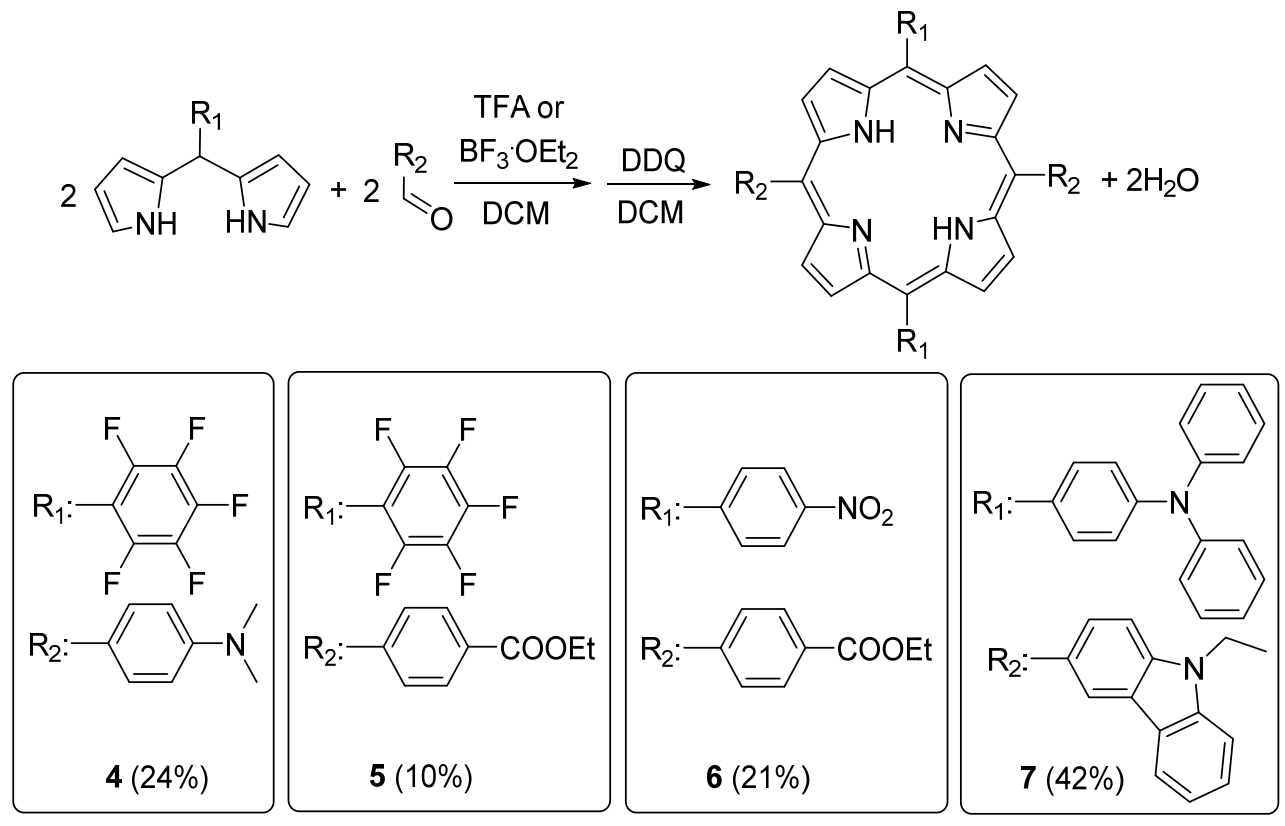

Scheme 2. Synthesis of ABAB-porphyrins 4-7.

\subsection{UV-Visible Absorption Spectroscopic Properties}

Porphyrin 4-7 showed the typical Soret band at $\sim 420-430 \mathrm{~nm}$ and the four Q-bands between $512-653 \mathrm{~nm}$, which are characteristics of meso-tetraphenylporphyrin derivatives $[5,6]$. The spectroscopic properties of the porphyrins are summarized in Table 1 . The $Q$ band of the free base porphyrin moiety consists of four components: $Q_{\times}(0,0), Q_{\times}(1,0)$, $Q_{y}(0,0)$ and $Q_{y}(1,0)$, which are associated with $D_{2 h}$ symmetry [13]. The maximum of the Soret band of carbazoyl porphyrin derivative 7 showed a $10 \mathrm{~nm}$ bathochromic shift with respect to 5,10,15,20-tetrakis(phenyl)porphyrin in DMF due to the auxochromic effect of the carbazoyl groups [14].

The steady-state fluorescence emission spectra of these porphyrins were obtained in DMF (Table 1). The two bands are characteristic for similar meso-substituted porphyrin, which were assigned to $Q_{x}(0-0)$ and $Q_{x}(0-1)$ transitions $[5,6]$. Free-base porphyrins with $\mathrm{D}_{2 \mathrm{~h}}$ symmetry displayed vibronic structure unchanged upon excitation. Moreover, Stokes shifts of $\sim 10 \mathrm{~nm}$ were obtained for the tetrapyrrolic macrocycles from the intersection of the absorption and fluorescence $Q_{\times}(0-0)$ band. Therefore, the spectroscopic energies of these porphyrins were similar to the relaxed energies of the lowest singlet excited state $\mathrm{S}_{1}$. This behavior was in accordance with a rigid planar structure of tetrapyrrolic macrocycles. Fluorescence quantum yields $\left(\Phi_{\mathrm{F}}\right)$ of these photosensitizers were calculated by comparison with TMP as a reference. The values of $\Phi_{\mathrm{F}}$ for these porphyrins agree with values previously reported by similar porphyrin derivatives $[5,15]$.

Table 1. Spectroscopic properties of porphyrins 4-7 in N,N-dimethylformamide (DMF).

\begin{tabular}{ccccc}
\hline PS & Absorption $_{\max }(\mathbf{n m})$ & $\varepsilon^{\text {Soret a }}$ & Fluorescence $\max (\mathbf{n m})$ & $\boldsymbol{\Phi}_{\mathbf{F}} \mathbf{b}$ \\
\hline $\mathbf{4}$ & 418510542589647 & $4.67 \times 10^{5}$ & 651712 & $0.063 \pm 0.003$ \\
$\mathbf{5}$ & 420512543590648 & $4.72 \times 10^{5}$ & 652712 & $0.054 \pm 0.002$ \\
$\mathbf{6}$ & 421516551591647 & $4.72 \times 10^{5}$ & 652717 & $0.10 \pm 0.01$ \\
$\mathbf{7}$ & 428520563596653 & $3.15 \times 10^{5}$ & 668729 & $0.12 \pm 0.01$ \\
\hline
\end{tabular}

a molar absorption coefficient $\left(\mathrm{L} \mathrm{mol}^{-1} \mathrm{~cm}^{-1}\right),{ }^{b}$ fluorescence quantum yield. 


\section{Conclusions}

The following two basic steps were used sequentially in the synthesis of ABAB-porphyrin: (1) meso-(4-substituted) dipyrromethane was formed from correspondent benzaldehyde derivative and pyrrole catalyzed by acid, (2) condensation of dipyrromethane with appropriate benzaldehydes yields the ABAB-porphyrin, which was easily purified by flash chromatography. Thus, the desired ABAB-porphyrins 4-7, bearing different substituents were obtained with appreciable yields of $10-42 \%$. Thus, the dipyrromethanes react with an aldehyde under the conditions of the two-step one-flask porphyrin synthesis, affording direct access to ABAB-porphyrins. Moreover, it has a relatively simple reaction workup and high yields. These trans-substituted porphyrins contain precursor groups of positive charges, which can be used to obtain cationic photosensitizers. Moreover, these tetrapyrrolic macrocycles can be covalently attached to molecular structures and be used to form polymeric materials. Therefore, these ABAB-porphyrins are interesting starting materials to obtain photoactive molecular structures as potential phototherapeutic agents.

Acknowledgments: This work was supported by CONICET, PIP-2015 11220150100197 CO, UNRC-SECYT, PPI-2020 and ANPCYT, PICT 0667/16. M.E.M. and E.N.D. are Scientific Members of CONICET. M.E.P. thanks CONICET for the research fellowship.

Conflicts of Interest: The authors declare no conflict of interest.

\section{References}

1. Martinez De Pinillos Bayona, A.; Mroz, P.; Thunshelle, C.; Hamblin, M.R. Design features for optimization of tetrapyrrole macrocycles as antimicrobial and anticancer photosensitizers. Chem. Biol. Drug. Des. 2017, 89, 192-206.

2. Alves, E.; Faustino, M.A.F.; Neves, M.G.P.M.S.; Cunha, Â.; Nadais, H.; Almeida, A. Potential applications of porphyrins in photodynamic inactivation beyond the medical scope. J. Photochem. Photobiol. C Photochem. Rev. 2015, $22,34-57$.

3. Heredia, D.A.; Martínez, S.R.; Durantini, A.M.; Pérez, M.E.; Mangione, M.I.; Durantini, J.E.; Gervaldo, M.A.; Otero, L.A.; Durantini, E.N. Antimicrobial photodynamic polymeric films bearing biscarbazol triphenylamine end-capped dendrimeric $\mathrm{Zn}$ (II) porphyrin. ACS Appl. Mater. Interfaces 2019, 11, 27574-27587.

4. Scanone, A.C.; Gsponer, N.S.; Alvarez, M.G.; Heredia, D.A.; Durantini, A.M.; Durantini, E.N. Magnetic nanoplatforms for in situ modification of macromolecules: Synthesis, characterization and photoinactivating power of cationic nanoiman-porphyrin conjugates. ACS Appl. Bio Mater. 2020, 3, 5930-5940.

5. Ballatore, M.B.; Spesia, M.B.; Milanesio, M.E.; Durantini, E.N. Synthesis, spectroscopic properties and photodynamic activity of porphyrin-fullerene $\mathrm{C}_{60}$ dyads with application in the photodynamic inactivation of Staphylococcus aureus. Eur. J. Med. Chem. 2014, 83, 685-694.

6. Scanone, A.C.; Gsponer, N.S.; Alvarez, M.G.; Durantini, E.N. Porphyrins containing basic aliphatic amino groups as potential broad-spectrum antimicrobial agents. Photodiagn. Photodyn. Ther. 2018, 24, 220-227.

7. Durantini, E.N.; Silber, J.J. Synthesis of 5-(4-acetamidophenyl)-10,15,20-tris(4-substituted phenyl) porphyrins using dipyrromethanes. Synth. Commun. 1999, 29, 3353-3368.

8. Lindsey, J.S. Synthetic routes to meso-patterned porphyrins. Acc. Chem. Res. 2010, 43, 300-311.

9. Lee, C.; Lindsey, J.S. One-flask synthesis of meso-substituted dipyrromethanes and their application in the synthesis of transsubstituted porphyrin building blocks. Tetrahedron 1994, 50, 11427-11440.

10. Gutsche, C.S.; Ortwerth, M.; Gräfe, S.; Flanagan, K.J.; Senge, M.O.; Reissig, H.-U.; Kulak, N.; Wiehe, A. Nucleophilic aromatic substitution on pentafluorophenyl-substituted dipyrranes and tetrapyrroles as a route to multifunctionalized chromophores for potential application in photodynamic. Chem. Eur. J. 2016, 22, 13953-13964.

11. Megiatto, J.D.; Antoniuk-Pablant, A.; Sherman, B.D.; Kodis, G.; Gervaldo, M.; Moore, T.A.; Moore, A.L.; Gust, D. Mimicking the electron transfer chain in photosystem II with a molecular triad thermodynamically capable of water oxidation. Proc. Natl. Acad. Sci. USA 2012, 109, 15578-15583.

12. Durantini, J.; Morales, G.M.; Santo, M.; Funes, M.; Durantini, E.N.; Fungo, F.; Dittrich, T.; Otero, L.; Gervaldo, M. Synthesis and characterization of porphyrin electrochromic and photovoltaic electropolymers. Org. Electron. 2012, 13, 604-614.

13. Baskin, J.S.; Yu, H.Z.; Zewail, A.H. Ultrafast dynamics of porphyrins in the condensed phase: I. free base tetraphenylporphyrin. J. Phys. Chem. A 2002, 106, 9837-9844.

14. Mora, S.J.; Cormick, M.P.; Milanesio, M.E.; Durantini, N.E. The photodynamic activity of a novel porphyrin derivative bearing a fluconazole structure in different media and against Candida albicans. Dyes Pigm. 2010, 87, 234-240.

15. Kooriyaden, F.R.; Sujatha, S.; Arunkumar, C. Study of scrambling in porphyrin forming reactions: Synthesis, structure, photophysical, electrochemical and antimicrobial studies. Polyhedron 2017, 128, 85-94. 